\title{
Genome-wide expression profiling shows transcriptional reprogramming in Fusarium graminearum by Fusarium graminearum virus 1-DK21 infection
}

\author{
Won Kyong Cho ${ }^{\dagger}$, Jisuk Yư ${ }^{\dagger}$, Kyung-Mi Lee, Moonil Son, Kyunghun Min, Yin-Won Lee and Kook-Hyung Kim
}

\begin{abstract}
Background: Fusarium graminearum virus 1 strain-DK21 (FgV1-DK21) is a mycovirus that confers hypovirulence to F. graminearum, which is the primary phytopathogenic fungus that causes Fusarium head blight (FHB) disease in many cereals. Understanding the interaction between mycoviruses and plant pathogenic fungi is necessary for preventing damage caused by F. graminearum. Therefore, we investigated important cellular regulatory processes in a host containing FgV1-DK21 as compared to an uninfected parent using a transcriptional approach.

Results: Using a 3'-tiling microarray covering all known F. graminearum genes, we carried out genome-wide expression analyses of $F$. graminearum at two different time points. At the early point of growth of an infected strain as compared to an uninfected strain, genes associated with protein synthesis, including ribosome assembly, nucleolus, and ribosomal RNA processing, were significantly up-regulated. In addition, genes required for transcription and signal transduction, including fungal-specific transcription factors and cAMP signaling, respectively, were actively up-regulated. In contrast, genes involved in various metabolic pathways, particularly in producing carboxylic acids, aromatic amino acids, nitrogen compounds, and polyamines, showed dramatic down-regulation at the early time point. Moreover, genes associated with transport systems localizing to transmembranes were down-regulated at both time points.

Conclusion: This is the first report of global change in the prominent cellular pathways in the Fusarium host containing FgV1-DK21. The significant increase in transcripts for transcription and translation machinery in fungal host cells seems to be related to virus replication. In addition, significant down-regulation of genes required for metabolism and transporting systems in a fungal host containing the virus appears to be related to the host defense mechanism and fungal virulence. Taken together, our data aid in the understanding of how FgV1-DK21 regulates the transcriptional reprogramming of $F$. graminearum.
\end{abstract}

\section{Background}

Fusarium graminearum (teleomorph Gibberella zeae) is a well known phytopathogenic fungus associated with Fusarium head blight (FHB) disease, which causes blights, root rots, or wilts, especially in economically important cereal crops such as wheat, maize, and barley

\footnotetext{
* Correspondence: kookkim@snu.ac.kr

${ }^{\dagger}$ Equal contributors

Department of Agricultural Biotechnology, Center for Fungal Pathogenesis and Research Institute for Agriculture and Life Sciences, Seoul National University, Seoul 151-921, Republic of Korea
}

[1]. FHB is considered an important fungal disease because it drastically reduces grain yield and quality, and produces mycotoxins such as deoxynivalenol (DON) and nivalenol (NIV) in cereals, which are very harmful to human and animal health $[2,3]$. The fungus can also infect several dicotyledonous plants including Arabidopsis, tobacco, tomato, and soybean [4].

Viruses that infect plant fungi are referred to as mycoviruses. Infection by some mycoviruses confers hypovirulence by attenuating pathogenicity to their fungal hosts, which are mostly plant pathogens. Mycoviruses tend to be double-stranded RNA (dsRNA) 
viruses [5], and several Fusarium-infecting mycoviruses have been isolated [6-8]. In addition, several whole genome sequences of dsRNA mycoviruses strains derived from $F$. graminearum have recently been reported [9-12].

In many cases, such as those of $F$. poae (Fusarium poae virus 1, FpV1) [7] and F. solani (Fusarium solani virus 1, FsV1), viral infection is not associated with phenotypic changes [8]. However, Fusarium graminearum virus 1 strain-DK21 (FgV1-DK21) exhibits interesting phenotypes including reduced mycelial growth and the induction of dark red pigmentation [6]. Several previous studies have provided strong evidence that hypovirulent mycoviruses could be used as substitutes for fungicides $[13,14]$. A recent study demonstrated that protoplast fusion is the most efficient approach for transmitting mycoviruses among a wide range of phytopathogenic fungi and that this approach will facilitate the use of mycoviruses as a biocontrol agent [15].

With the increasing availability of whole genome sequences for representative plant fungal pathogens [16], extensive and diverse genome-wide analyses can be performed, including transcriptomics, proteomics, and metabolomics [17]. Proteomics approaches for different Fusarium species have enabled examinations of extracellular proteins, proteins involved in fumonisin biosynthesis, and proteome profiles upon antagonistic rhizobacteria inoculation and mycovirus infection [18-21]. Several gene expression analyses based on microarrays have also been conducted [21-25]. For example, genome-wide expression profiling of $F$. graminearum was carried out to examine responses to treatment with azole fungicide tebuconazole and during perithecium development $[22,24]$. Microarrays provide a valuable tool for detecting and identifying Fusarium species that produce specific metabolites such as trichothecene and moniliformin [23,25]. Moreover, the recently completed genome sequencing of three major Fusarium species provides an important resource for studying pathogenicity and functions of individual genes [26].

Several microarray-based studies have demonstrated transcriptional changes in fungal genes following mycovirus infection, although most of these studies examined only CHV1-713 infecting the chestnut blight fungus Cryphonectria parasitica. Initially, a polymerase chain reaction (PCR)-based approach demonstrated that elevation of cAMP levels by CHV1-713 resulted in reduced accumulation of the GTP-binding (G) protein subunit CPG-1 [25]. In addition, cDNA microarrays containing 2,200 genes from C. parasitica showed transcriptional change in G-signaling pathways following hypovirus infections showing different virulence or phenotypes [27-29].

Infection by a virus leads to changes in diverse biological processes between fungal host and viral factors. It is of interest to examine such alterations at the molecular level.
However, no previous reports have examined expression differences between a fungus containing a mycovirus and an infected parent, aside from two papers that used microarray cDNA chips based on expressed sequence tags to examine fungal host gene expression upon mycovirus infection $[28,29]$. Here, we examined genomewide transcriptional differences in F. graminearum expression between a strain harboring FgV1-DK21 and its uninfected parent. This is the first report of a genome-wide fungal gene expression analysis during mycovirus infection using a 3 ' tiling microarray, and our findings show global differences in host cellular pathways in F. graminearum harboring FgV1-DK21.

\section{Results}

Genome-wide 3'-tiling microarray to identify differentially expressed genes in F. graminearum harboring FgV1-DK21 The virus-infected F. graminearum exhibited strong inhibition of mycelia growth as well as reduced levels of DON at 7 days after inoculation (Figure 1). To visualize how gene expression patterns were affected at different time points, we generated scatterplots (Figure 2).

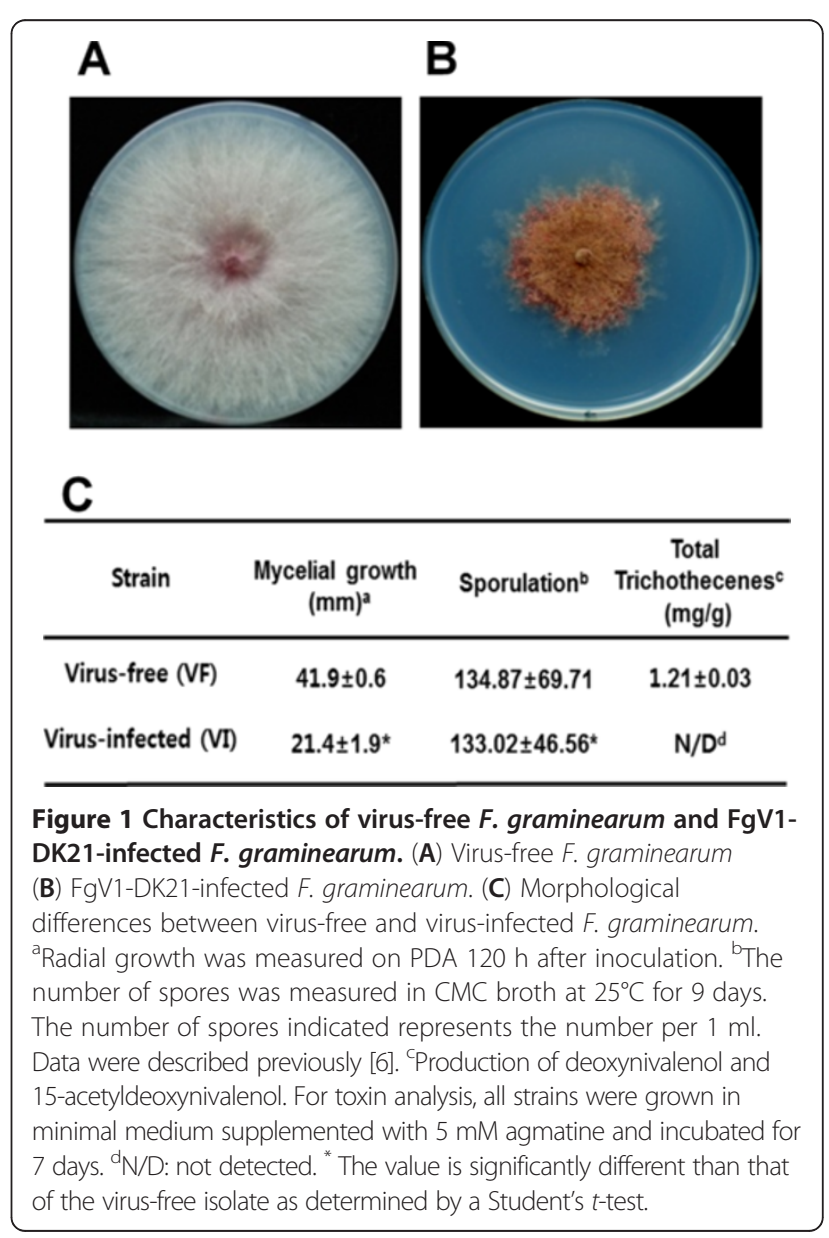



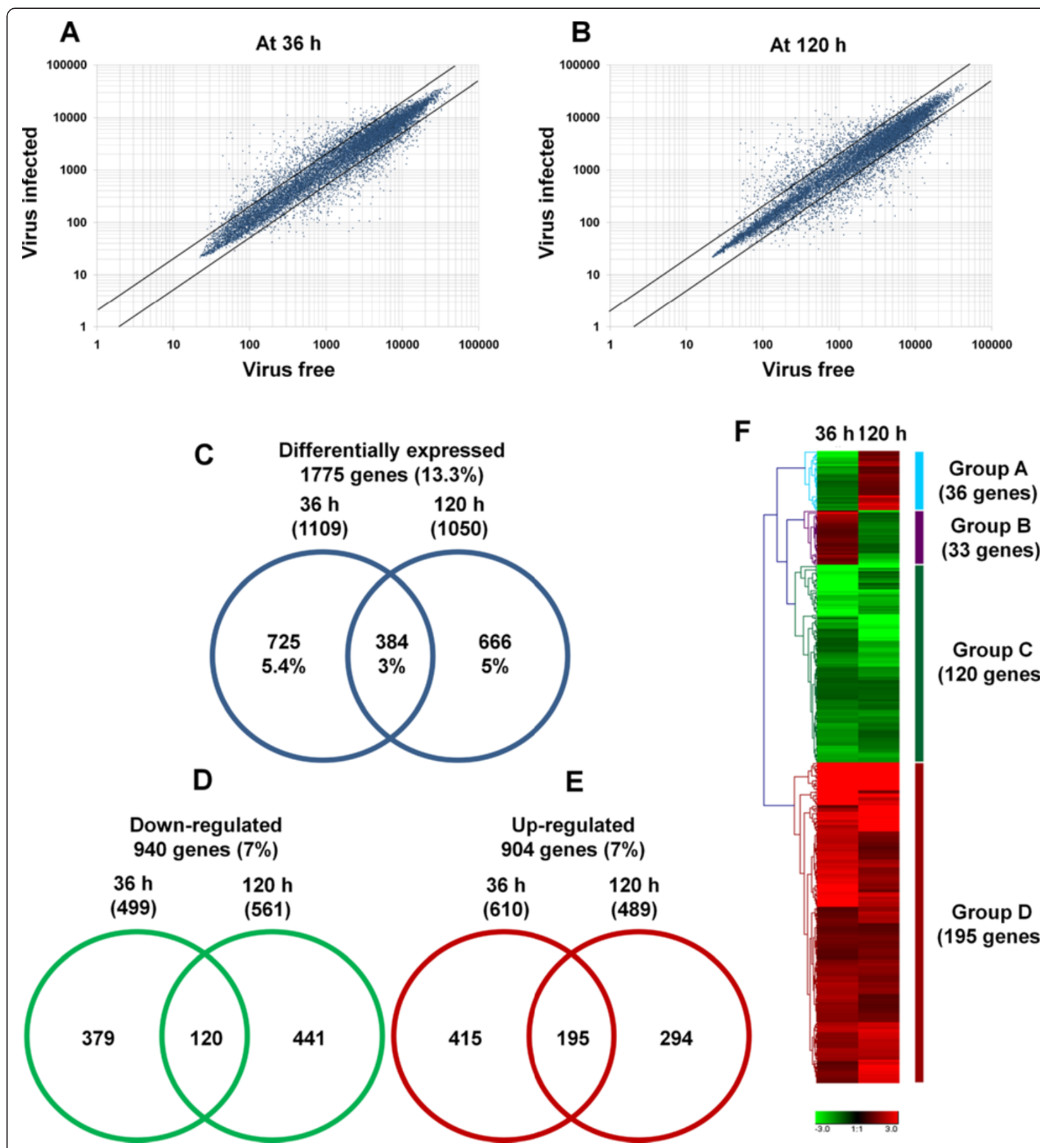

Figure 2 Differentially expressed F. graminearum genes during FgV1-DK21 infection identified by microarray. Scatterplots of normalized signal intensities $36 \mathrm{~h}(\mathbf{A})$ and $120 \mathrm{~h}$ (B) after inoculation with FgV1-DK21 as compared to virus-free samples. All signal intensities were converted to a $\log 10$ scale. The diagonal lines indicate a two-fold change. The Venn diagram illustrates the total number of genes that were significantly differentially expressed at $36 \mathrm{~h}$ and $120 \mathrm{~h}(\mathbf{C})$, down-regulated genes (D), and up-regulated genes (E). The heat map shows the expression patterns of 384 genes that were hierarchically clustered and differentially expressed at both 36 and $120 \mathrm{~h}(\mathbf{F})$. Red and green indicate upregulation and down-regulation, respectively.

Interestingly, the scatterplots showed that there were no significant differences in the number of differentially expressed genes between $36 \mathrm{~h}$ and $120 \mathrm{~h}$; however, it appeared that the changes in gene expression at $120 \mathrm{~h}$ were somewhat more extensive than those at $36 \mathrm{~h}$ (Figure 2). To identify differentially expressed genes, we first performed hierarchical clustering, which identified gene sets of significantly differentially expressed genes at 
two different time points (Additional file 1: Table S1 and Additional file 2: Table S2). Most of the identified genes showed at least two-fold differential expression. A total of 1775 genes, representing $13.3 \%$ of 13,382 genes, were differentially expressed at both time points (Figure 2C), with 1109 (5.4\%) and 1050 genes (5\%) identified as differentially expressed at $36 \mathrm{~h}$ and $120 \mathrm{~h}$, respectively (Figure 2C). Moreover, 384 genes (3\%) were differentially expressed at both time points (Figure 2C).

We further analyzed the lists of differentially expressed genes according to those down-regulated vs. those upregulated (Figure 2D, E). Genes with an adjusted P-value less than 0.05 were selected as differentially expressed genes. In both time points, 940 genes (7\%) were downregulated whereas 904 genes (7\%) were up-regulated (Figure 2D, E). Among the down-regulated genes, there were more differentially expressed genes at $120 \mathrm{~h}$ (561 genes) than at $36 \mathrm{~h}$ (499 genes) (Figure 2D). In contrast, more genes were induced at $36 \mathrm{~h}$ (610 genes) than at $120 \mathrm{~h}$ (489 genes) (Figure 2E). Moreover, 120 genes and 195 genes were commonly found in the group of downregulated and up-regulated genes, respectively (Figure 2D, E). We then investigated the expression patterns of 384 genes that were differentially expressed at both time points using hierarchical clustering, which sorted the genes into four groups according to expression patterns (Figure 2F). Group A contained 36 genes that were highly downregulated at $36 \mathrm{~h}$ but were up-regulated at $120 \mathrm{~h}$. In contrast, the 33 genes belonging to group $\mathrm{B}$ were highly induced at $36 \mathrm{~h}$, and subsequently down-regulated (Figure 2F). Group C included 120 genes that were strongly repressed regardless of virus infection time, and group D contained 195 genes that showed consistently elevated gene expression across both time points.

\section{Representative genes showing significant expression change and real-time validation of the microarray data by quantitative real-time reverse transcription PCR}

Representative fungal genes that showed significant gene expression are listed in Table 1 . At $36 \mathrm{~h}$, several genes encoding enzymes including phospholipase/carboxylesterase, polyketide synthase, eukaryotic aspartyl protease and dipeptidyl aminopeptidases were highly induced, whereas transcripts involved in transport, such as amino acid transporter permease and $A B C$ transporter, were up-regulated at $120 \mathrm{~h}$ (Table 1). In contrast, several of the repressed genes at $36 \mathrm{~h}$ included maltose transporter, linoleate diol synthase, and genes with unknown functions, whereas those encoding ferric reductase and abhydrolase 3 were strongly repressed at $120 \mathrm{~h}$ (Table 1).

To validate the microarray data, we selected 20 genes whose expression was significantly affected in the host containing FgV1-DK21, as demonstrated by the microarray analysis, and determined their relative expression by quantitative real-time reverse transcription PCR (qRT-PCR) (Figure 3 and Additional file 3: Table S3 and Additional file 4: Table S4). Genes that showed diverse expression patterns were categorized into different functional classes (Figure 3 and Additional file 3: Table S3). The results of the qRT-PCR were highly consistent with those of the microarray data. For example, according to the qRT-PCR and microarray results, the transcript levels for three genes, including FGSG_01379, FGSG_03143, and FGSG_03911, were highly reduced at both $36 \mathrm{~h}$ and 120 h, whereas FGSG_03788, FGSG_00023, FGSG_07804, FGSG_07801, and FGSG_13222 were strongly induced regardless of the time point (Figure $3 \mathrm{~A}-\mathrm{C}$ ). When the mRNA level of a gene is too low to quantify, or the P-values from the microarray data are very high, it is highly likely that qRT-PCR results will not correlate with microarray data, as was observed for FGSG_11119 and FGSG_04089 (Figure 3A). As compared to the microarray approach, qRT-PCR offers a highly sensitive technique for detecting low amounts of transcripts and provides the transcript level for the gene of interest. For example, the expression intensities for 11 genes were relatively low, ranging from 0 to 2.97 (Figure 3A), whereas the amount of mRNAs for NAD-dependent aldehyde dehydrogenases (FGSG_07801) and dipeptidyl aminopeptidases (FGSG_13222) were very high and ranged from 4424.26 to 5254.08 , particularly in the host containing FgV1-DK21 at $36 \mathrm{~h}$ (Figure 3C).

\section{FunCat classification for an overview of the transcriptional reprogramming of $F$. graminearum harboring FgV1-DK21}

We subjected a total of 1775 differentially expressed genes to functional catalogue (FunCat) annotation to gain insight into their functional classifications [29]. Specifically, we divided differentially expressed genes into four groups (Table 2). More than half of the differentially expressed genes were not assigned to any functional category. Specifically, 344 genes $(71.9 \%)$ in the group of down-regulated genes at $120 \mathrm{~h}$ were unclassified. Of the functional categories, the vast majority of differentially expressed genes were associated with metabolism (Table 2). Note that 118 genes (28.2\%) were downregulated while 81 genes $(22.9 \%)$ were up-regulated at $36 \mathrm{~h}$, whereas there were more up-regulated genes (95) than down-regulated genes (79) at $120 \mathrm{~h}$. Based on the number of differentially expressed genes, it is likely that genes involved in various metabolic pathways were severely repressed at $36 \mathrm{~h}$ and then were gradually induced at $120 \mathrm{~h}$. Along with a gene set for metabolism, genes associated with energy were highly down-regulated (26 genes) at $36 \mathrm{~h}$ (Table 2). In contrast, genes involved in transcriptional and translational machinery were dominantly up-regulated early after FgV1-DK21 infection. For 
Table 1 Representative $F$. graminearum genes exhibiting significant differential expression levels in microarray analysis

\begin{tabular}{|c|c|c|c|c|}
\hline Gene locus & Function & $\log _{2} F C$ & P-value & Time point \\
\hline \multicolumn{5}{|c|}{ Ten representative up-regulated genes } \\
\hline FGSG_07801 & Phospholipase/Carboxylesterase & 6.487887158 & 0.001776791 & $36 \mathrm{~h}$ \\
\hline FGSG_07798 & Polyketide synthase & 6.350204512 & 0.001744378 & $36 \mathrm{~h}$ \\
\hline FGSG_07800 & Eukaryotic aspartyl protease & 6.046050259 & 0.004179133 & $36 \mathrm{~h}$ \\
\hline FGSG_13222 & Dipeptidyl aminopeptidases & 5.960147173 & 0.003763144 & $36 \mathrm{~h}$ \\
\hline FGSG_07804 & Cytochrome P450 & 5.427966104 & 0.011883416 & $36 \mathrm{~h}$ \\
\hline FGSG_04468 & Amino acid transporter permease & 4.672200299 & 0.012719315 & $120 \mathrm{~h}$ \\
\hline FGSG_08055 & Amino acid transporter permease & 4.288189196 & 0.013683756 & $120 \mathrm{~h}$ \\
\hline FGSG_03788 & Glyco_hydrolase_16 & 4.044638062 & 0.013683756 & $120 \mathrm{~h}$ \\
\hline FGSG_05076 & $\mathrm{ABC}$ transporter & 3.965527131 & 0.012719315 & $120 \mathrm{~h}$ \\
\hline FGSG_03687 & Esterase lipase & 3.836457968 & 0.012719315 & $120 \mathrm{~h}$ \\
\hline \multicolumn{5}{|c|}{ Ten representative down-regulated genes } \\
\hline FGSG_03911 & Maltose transporter & -5.371438178 & 0.046804957 & $36 \mathrm{~h}$ \\
\hline FGSG_02668 & Linoleate diol synthase & -5.234881513 & 0.014192107 & $36 \mathrm{~h}$ \\
\hline FGSG_10572 & unknown function & -4.787897398 & 0.028984152 & $36 \mathrm{~h}$ \\
\hline FGSG_11146 & Linoleate diol synthase & -4.688195689 & 0.027402009 & $36 \mathrm{~h}$ \\
\hline FGSG_04795 & unknown function (DUF1612) & -4.567155895 & 0.013485652 & $36 \mathrm{~h}$ \\
\hline FGSG_03143 & Glycosyl hydrolase 88 & -5.893401797 & 0.018275961 & $120 \mathrm{~h}$ \\
\hline FGSG_03737 & Major facilitator & -5.229057946 & 0.012719315 & $120 \mathrm{~h}$ \\
\hline FGSG_04780 & Ferric reductase & -4.889869656 & 0.03402279 & $120 \mathrm{~h}$ \\
\hline FGSG_11119 & Ferric reductase & -4.796036501 & 0.015887627 & $120 \mathrm{~h}$ \\
\hline FGSG_03738 & Abhydrolase 3 & -4.655190203 & 0.015033887 & $120 \mathrm{~h}$ \\
\hline
\end{tabular}

example, genes associated with the cell cycle and DNA processing (21 genes), transcription (46 genes), protein synthesis (35 genes), protein fate (18 genes), and those encoding proteins with binding function (81 genes) were highly upregulated at $36 \mathrm{~h}$. The number of down-regulated genes associated with cellular transport at $36 \mathrm{~h}$ was almost twice that of up-regulated genes. Conversely, the number of upregulated genes that govern cellular transport was similar to that of the down-regulated genes at $120 \mathrm{~h}$.

\section{FgV1-DK21 changes the transcript levels of fungal genes involved in ribosome biogenesis}

Next, we analyzed the enriched gene ontology (GO) terms of the differentially expressed genes. The identified enriched GO terms are listed in Additional file 5: Table S5. The directed acyclic graph (DAG) illustrates the GO terms that were over-represented (Figures 4, 5, 6, 7, 8, and 9). Interestingly, GO terms related to ribosome biogenesis, such as the ribosome ribonucleoprotein complex assembly (GO: 0022618), ribosome assembly (GO: 0042255), ribonucleoprotein complex biogenesis (GO: 0022613), and ribosome biogenesis (GO: 0042254), were highly over-represented
(Figure 4). Moreover, GO terms for RNA processing (GO: 0006396), ncRNA processing (GO: 0034470), rRNA metabolic processes (GO: 0016072), rRNA processing (GO: 0006364), and maturation of SSU-rRNA (GO: 0030490) were over-represented with high levels of transcripts (Figure 5). Similarly, GO terms related to the nucleolus, such as the small nucleolar ribonucleoprotein complex (GO: 0005732), the nuclear lumen (GO: 0031981), and nucleolus (GO: 0005730), were over-represented (Figure 6). Transcripts associated with the nucleolus were highly accumulated at $36 \mathrm{~h}$.

Influence of FgV1-DK21 on fungal host gene expression related to metabolic pathways and stress responses It was not surprising that the expressions of genes that involve a range of metabolic pathways were significantly affected by FgV1-DK21 infection. Consistent with the FunCat annotation, GO enrichment analysis showed that genes associated with a variety of metabolic pathways were significantly down-regulated, particularly at $36 \mathrm{~h}$. For example, over-represented GO terms included cellular aromatic compound metabolic processes (GO: 0006725), 


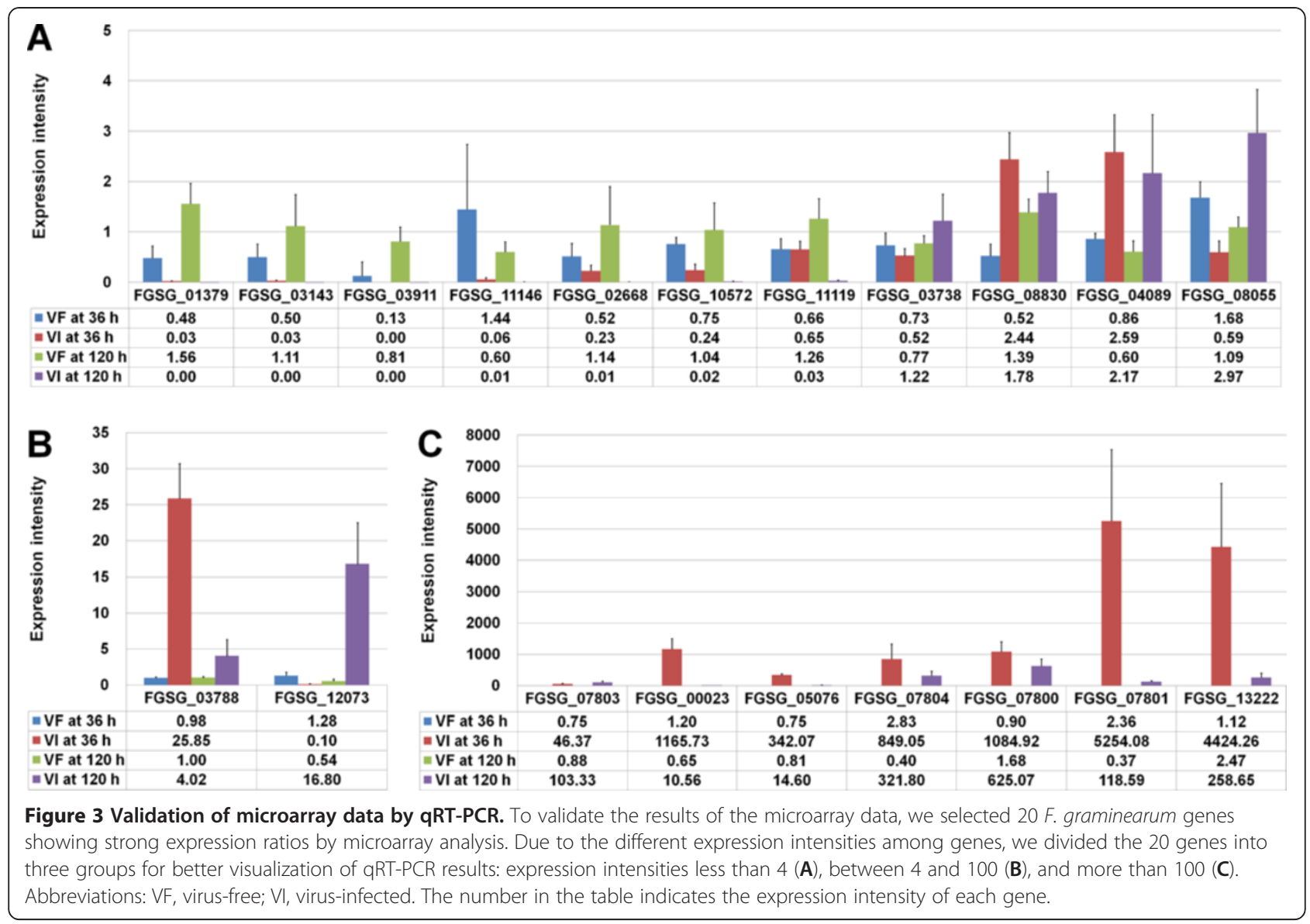

organic acid metabolic processes (GO: 0006082), oxoacid metabolic processes (GO: 0043436), carboxylic acid metabolic processes (GO: 0019752), chorismate metabolic processes (GO: 0046417), aromatic amino acid family biosynthetic processes (GO: 0009073), quinate metabolic processes (GO: 0019630), amine metabolic processes (GO: 0009308), and cellular nitrogen compound biosynthetic processes (GO: 0044271) (Figure 5). Most genes related to over-represented metabolic pathways tended to be downregulated at $36 \mathrm{~h}$. In contrast, the molecular functions for those genes were consistent with the highly up-regulated GO terms for transferase activity, transferring nitrogenous group (GO: 0016769), transaminase activity (GO: 0008483), and $\mathrm{N}$-acetyltransferase activity (GO: 0008080) at $120 \mathrm{~h}$ (Figure 7).

In particular, genes involved in several stress responses, such as to chemical stimulus (GO: 0042221), organic substances (GO: 0010033), and cAMP (GO: 0051591), were up-regulated, especially at $120 \mathrm{~h}$ (Figure 8). Of the identified GO terms, those reflecting interactions with the fungal host (GO: 0051701) as well as growth or development of symbionts during interactions with the fungal host (GO: 0052108) at $36 \mathrm{~h}$ are expected results (Figure 8). All genes associated with host interactions showed highly down-regulated gene expression.

\section{Down-regulation of membrane-associated transporter genes}

In the cellular component ontology, GO terms associated with membranes (GO terms 0016020, 0044425, 0031224, and 0016021) were over-represented (Figure 6). Interestingly, genes associated with membranes were down-regulated regardless of the time point (Figure 6). Furthermore, transporter activity was one of the significantly over-represented GO terms with respect to molecular function. Of a total of $17 \mathrm{GO}$ terms for transporter activity, 14 were present at $36 \mathrm{~h}$, including carbohydrate transmembrane transporter activity (GO: 0015144), ion transmembrane transporter activity (GO: 0015075), and sugar:hydrogen symporter activity (GO: 0005351) (Figure 9). At $120 \mathrm{~h}$, three GO terms, including primary active transmembrane transporter activity (GO: 0015399), ATPase activity, and coupled to transmembrane movement of substances (GO: 0042626), were over-represented (Figure 9). 
Table 2 Gene functions of significantly differentially expressed $F$. graminearum genes based on annotation of functional categories in FunCat

\begin{tabular}{|c|c|c|c|c|c|}
\hline Functional category & $\begin{array}{c}\text { Down-regulation } \\
\text { at } 36 \mathrm{~h}\end{array}$ & $\begin{array}{c}\text { Up-regulation } \\
\text { at } 36 \mathrm{~h}\end{array}$ & $\begin{array}{c}\text { Down-regulation } \\
\text { at } 120 \mathrm{~h}\end{array}$ & $\begin{array}{l}\text { Up-regulation } \\
\text { at } 120 \mathrm{~h}\end{array}$ & Whole genome \\
\hline Metabolism & $118(28.2 \%)$ & $81(22.9 \%)$ & 79 (16.5\%) & $95(22.9 \%)$ & $2324(16.9 \%)$ \\
\hline Energy & $26(6.22 \%)$ & $12(3.39 \%)$ & $13(2.71 \%)$ & $15(3.62 \%)$ & $503(3.66 \%)$ \\
\hline Cell cycle and DNA processing & $7(1.67 \%)$ & $21(5.94 \%)$ & $2(0.41 \%)$ & $10(2.41 \%)$ & $660(4.81 \%)$ \\
\hline Transcription & $4(0.95 \%)$ & $46(13.0 \%)$ & $1(0.2 \%)$ & $7(1.69 \%)$ & $720(5.24 \%)$ \\
\hline Protein synthesis & N.D & 35 (9.91\%) & $1(0.2 \%)$ & $2(0.48 \%)$ & $370(2.69 \%)$ \\
\hline Protein fate & $9(2.15 \%)$ & $18(5.09 \%)$ & $9(1.88 \%)$ & $13(3.14 \%)$ & $920(6.70 \%)$ \\
\hline Protein with binding function & $40(9.56 \%)$ & $81(22.9 \%)$ & $24(5.02 \%)$ & $49(11.8 \%)$ & $1716(12.5 \%)$ \\
\hline Regulation of metabolism & N.D & $3(0.84 \%)$ & $3(0.62 \%)$ & $1(0.24 \%)$ & $242(1.76 \%)$ \\
\hline Cellular transport & 75 (17.9\%) & $38(10.7 \%)$ & $51(10.6 \%)$ & $52(12.5 \%)$ & $1391(10.1 \%)$ \\
\hline Cellular communication & $5(1.19 \%)$ & $11(3.11 \%)$ & $3(0.62 \%)$ & $4(0.96 \%)$ & $312(2.27 \%)$ \\
\hline Cell rescue, defense, and virulence & $28(6.69 \%)$ & $38(10.7 \%)$ & $29(6.06 \%)$ & $45(10.8 \%)$ & $859(6.26 \%)$ \\
\hline Interaction with the environment & $20(4.78 \%)$ & $21(5.94 \%)$ & $23(4.81 \%)$ & $26(6.28 \%)$ & $607(4.42 \%)$ \\
\hline Systemic interaction with the environment & N.D & $1(0.28 \%)$ & N.D & N.D & $12(0.08 \%)$ \\
\hline Cell fate & $2(0.47 \%)$ & $6(1.69 \%)$ & $4(0.83 \%)$ & $2(0.48 \%)$ & $240(1.74 \%)$ \\
\hline Development & $4(0.95 \%)$ & $1(0.28 \%)$ & $2(0.41 \%)$ & $1(0.24 \%)$ & $55(0.40 \%)$ \\
\hline Biogenesis of cellular components & $13(3.11 \%)$ & $18(5.09 \%)$ & $10(2.09 \%)$ & $13(3.14 \%)$ & $617(4.49 \%)$ \\
\hline Cell type differentiation & $1(0.23 \%)$ & $11(3.11 \%)$ & $3(0.62 \%)$ & $6(1.44 \%)$ & $273(1.98 \%)$ \\
\hline Unclassified & 241 (57.6\%) & 333 (54.59\%) & 344 (71.9\%) & 276 (66.6\%) & 8894 (64.8\%) \\
\hline
\end{tabular}

N.D. indicates that genes were not detected in a given functional category.

Gray indicates the number of genes that were significantly enriched.

\section{F. graminearum transcription factors participate in transcription regulation of the host containing FgV1- DK21}

Transcription factors (TFs) play a key role in signal transduction pathways by regulating gene expression to control biological processes [30]. Thus, it is of interest to understand their involvement in fungi-virus interactions at the transcriptional level. Whole genome sequences of $F$. graminearum show that there are at least 659 TFs divided into 44 families [31]. We identified more differentially expressed TFs at the early time point (57 TFs) than at the late time point (27 TFs) (Additional file 6: Table S6). Zn2Cys6 (42 TFs) was the most prevalent TF family, followed by the $\mathrm{C} 2 \mathrm{H} 2$ zinc finger (7 TFs) and bHLH (2 TFs) families. In addition, centromere protein B, DNA-binding region, homeodomain-like, Lambda repressor-like, DNA-binding, nucleic acid-binding, OB-fold, TF jumonji, and bZIP were also identified as TFs showing significant change at the transcript level (Additional file 6: Table S6). Zn2Cys6 (15 TFs) was also the most prominent TF family at the late time point, followed by $\mathrm{C} 2 \mathrm{H} 2$ zinc finger (3 TFs), bHLH (2 TFs), and bZIP (2 TFs) (Additional file 6: Table S6). Moreover, the gene expressions of TFs belonging to the Myb (a negative transcriptional regulator), TF jumonji, zinc finger (CCHCtype), and zinc finger (NF-X1-type) families were significantly changed. Recently, a mutant library of 657 putative TFs was established via homologous recombination in F. graminearum, providing a valuable resource to study gene regulation in fungus [32]. Thus, it might be of interest to compare phenotypes of mutants for the 75 differentially expressed TFs. Most TF knock-out mutants show distinct phenotypes. For example, five mutants for which members of the $\mathrm{C} 2 \mathrm{H} 2$ zinc finger family were deleted (FGSG_04083 and FGSG_12837) and Zn2Cys6 (FGSG_04901, FGSG_05789, and FGSG_09464) displayed abnormal phenotypes compared to wild type controls. Interestingly, the deletion of FGSG_04083 resulted in a hypervirulence phenotype. The expression of all five of these TFs was strongly up-regulated $36 \mathrm{~h}$ after virus infection. Two genes (FGSG_12837 and FGSG_09464) were highly expressed in both early and late time points. The ascospore was not formed in FGSG_12837 mutants, while that for FGSG_09464 exhibited increased resistance to oxidative stress.

\section{Discussion}

FgV1-DK21 drastically induces the expression of fungal host genes required for their replication

Perhaps the most striking finding of this study is that the host containing FgV1-DK21 accumulates transcripts associated with translation machinery, such as ribosome 


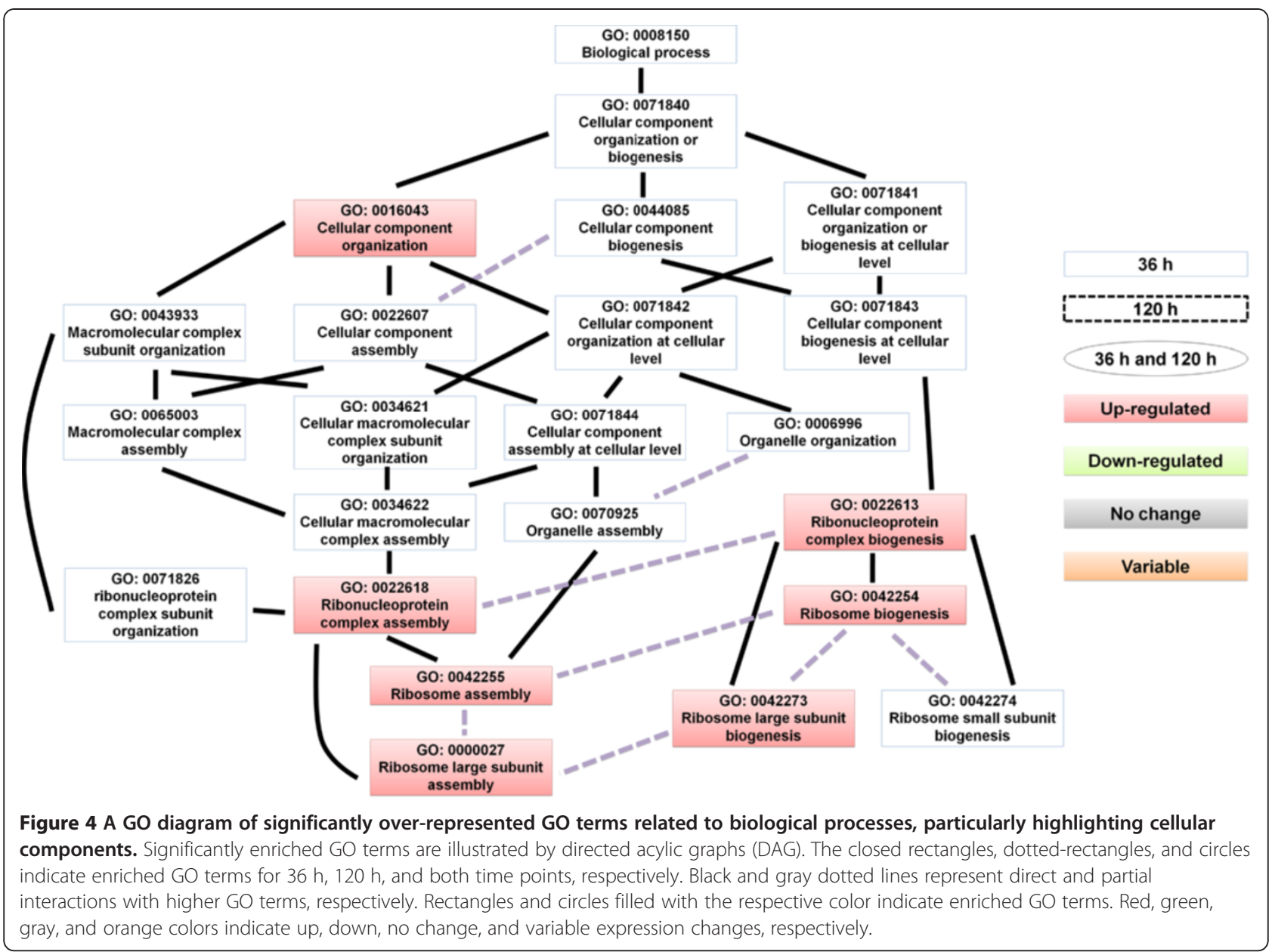

biogenesis and the nucleolus. Ribosomes function in the production of proteins, while the nucleolus is the site of ribosomal RNA synthesis and ribosome assembly [33]. The nucleolus actively participates in a variety of biological processes, including cell cycle regulation, cell growth, stress sensing, and viral infection [34]. Moreover, genes involved in RNA processing were highly induced. These genes convert precursor RNAs such as non-coding RNA (ncRNA) and small subunit (SSU) ribosomal RNAs molecules into mature RNA molecules. Taken together, these findings suggest that the entire complex for protein synthesis and processing in fungal host cells was highly activated by FgV1-DK21.

Viruses rely on host cell machinery and have evolved sophisticated mechanisms to achieve replication efficiently during virus infection [35]. Given that nucleolus localizing genes were up-regulated, it appears that the virus stimulates gene expression associated with nucleolus. As a result, the nucleolus produces numerous ribosomes to maximize viral replication. In addition, the virus might control protein synthetic machinery in host ribosomes to replicate viral proteins. Recently, proteomics- based studies confirmed the involvement of the nucleolus in viral infection and replication [36,37]. Previous studies have shown that RNA viruses can interact with several nucleolar proteins such as nucleolin, B23, and fibrillarin to facilitate virus replication [38]. Thus, it might be of interest to examine the interactions between nucleolar proteins from F. graminearum and FgV1-DK21 viral proteins in future studies. Although our data suggest that expression of genes related to ribosomes was strongly affected by virus infection, this might be a common phenomenon in hosts in response to various kinds of virus. Thus, we cannot exclude the possibility that ribosomes are indirectly involved in the replication of dsRNA viruses. Since little is known about dsRNA viruses, we refer to many results from singlestranded (ss) RNA viruses to support our data. The system for dsRNA viruses might differ from that of ssRNA viruses.

Genes associated with metabolic pathways play a critical role in the fungal defense mechanism against viral infection

Metabolism is the core of cellular functions, and comprises numerous reactions that function in the degradation of 


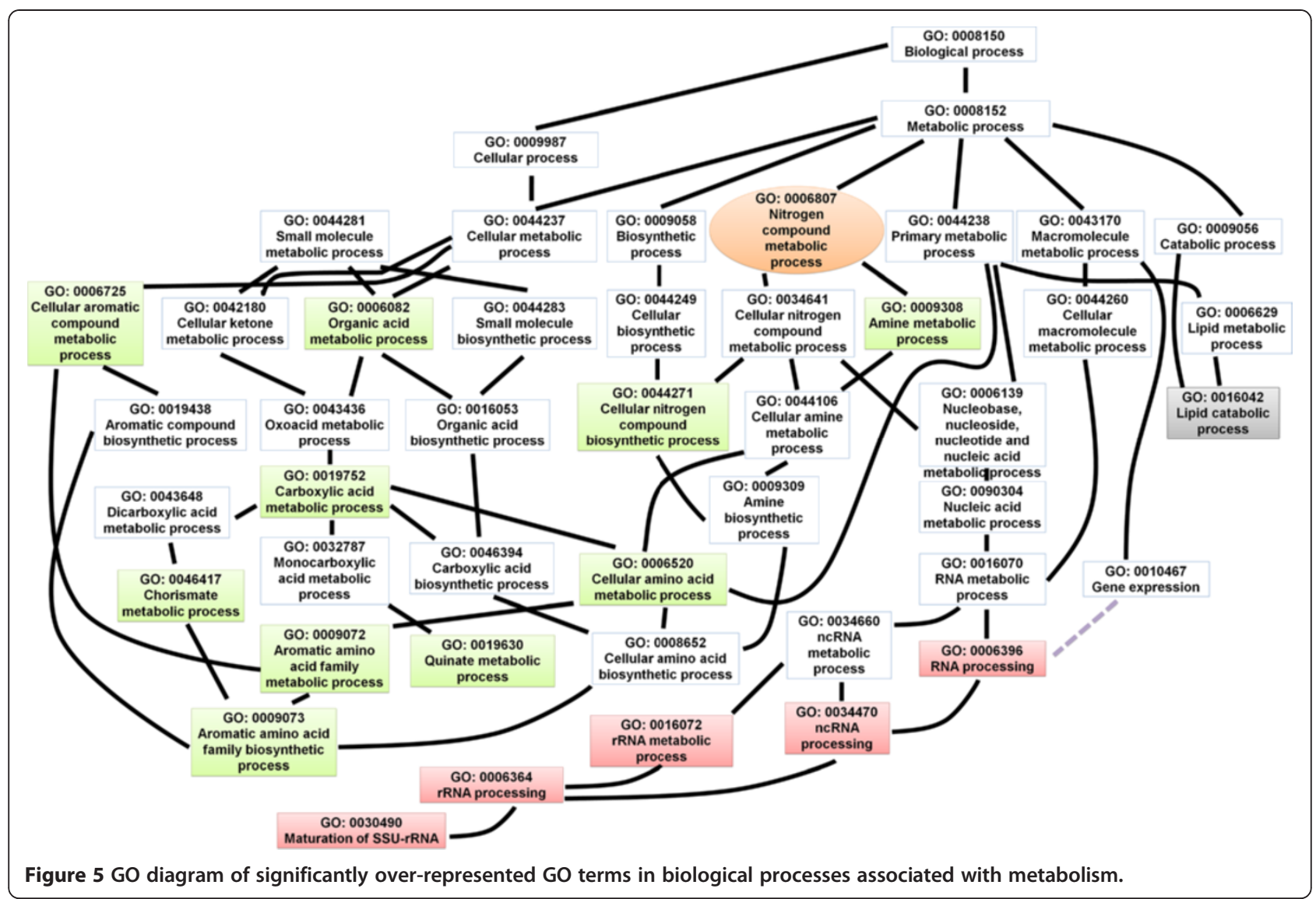

nutrients and biosynthesis of cellular components including proteins, lipids, carbohydrates, DNA, and RNA. Our results, as well as a previous report of $C$. parasitica, found dramatic differences in gene expression associated with metabolic pathways [39]. However, there are inherent differences between that study and the present one. Specifically, our microarray data demonstrated down-regulation of genes involved in metabolism. In contrast, the previous study found that the majority of metabolites, including lipids and carbohydrates, were significantly accumulated [39]. This difference may be due to different infection times. We found the most dramatic changes in gene expression at the early time point, whereas metabolic probing showed that a variety of metabolites accumulated with increasing infection time [39].

Differential expression of genes related to metabolism might be associated with the altered host phenotype. For example, in the group of down-regulated genes at $36 \mathrm{~h}$, genes for cell type differentiation were also highly enriched, suggesting that host cell differentiation seems to be induced by viral infection. Interestingly, several studies provide evidence that filamentous differentiation in fungi is required for virulence [40]. Regardless of viral infection stage, genes related to cell rescue, defense, and virulence were highly up-regulated, suggesting that the host defense system was consistently activated. Compared to the whole genome, genes with significantly enriched functions were mostly found in the group showing up-regulation at $36 \mathrm{~h}$, suggesting that the transcriptional regulation in the host harboring mycovirus is more important at the early time point than the late time point.

Of the altered metabolites, our study as well as a previous report [39] found dramatic changes in gene expression levels for polyamine production. Polyamines play roles in many biological processes, such as cell growth, development, and responses to various stresses [41]. Thus, it is likely that the down-regulation of genes involved in polyamine biosynthesis during the early stage (36 h) could be correlated with reduced levels of DON, which confers hypovirulence to host $F$. graminearum (Figure 1). A previous study showed that polyamine biosynthesis inhibitors decreased mycelial growth of Sclerotinia sclerotiorum [42]. This result is highly consistent with observed phenotypes in virus-infected $F$. graminearum showing strong inhibition of mycelia growth (Figure 1). However, we do not know whether the inhibition of mycelial growth in F. graminearum is directly related to polyamine biosynthesis. 


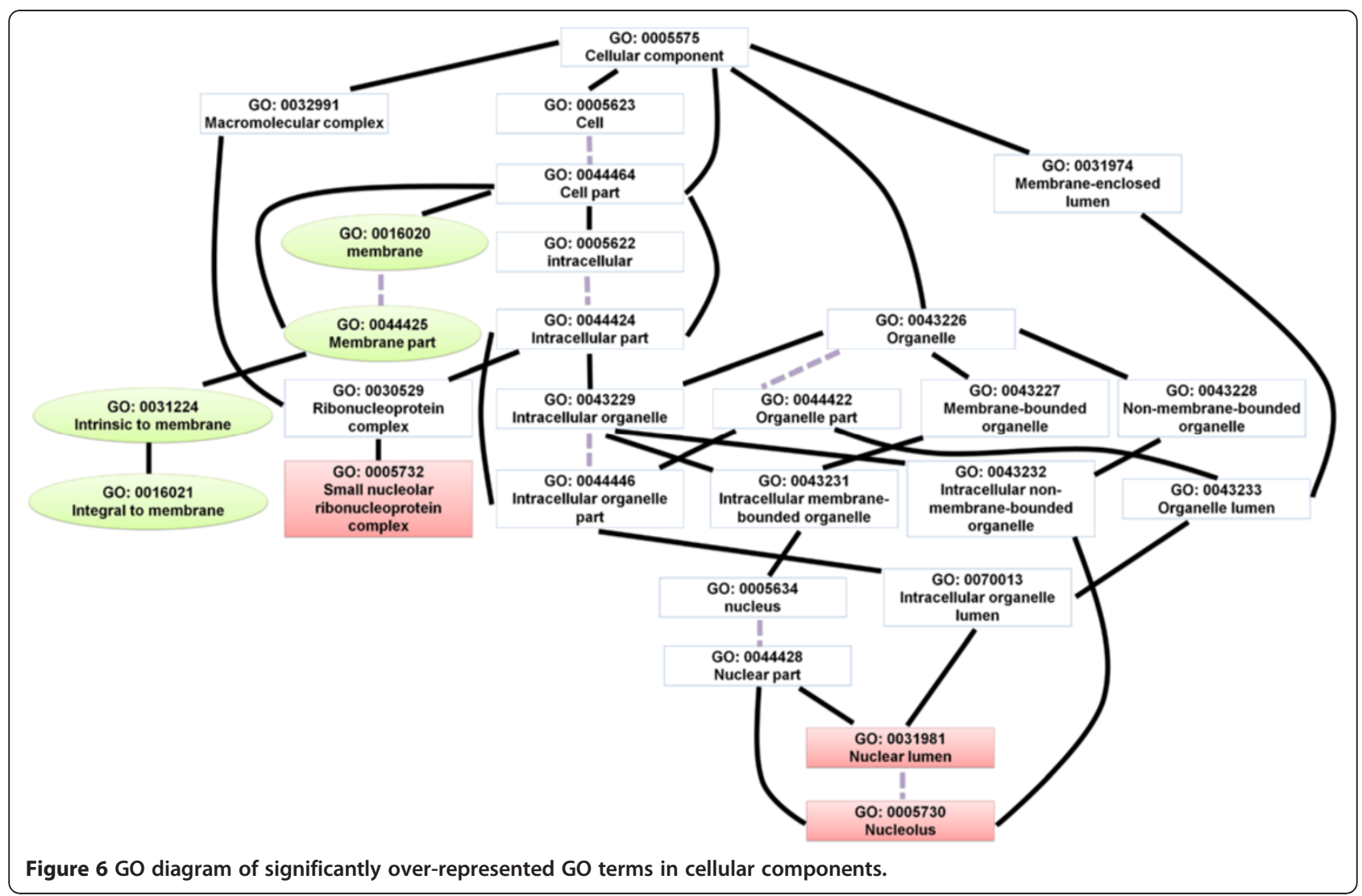

\section{Changes to the membrane-associated transporting system of the host harboring FgV1-DK21}

Along with the reduced amounts of many metabolites such as carbohydrates, gene expression for the transfer of such metabolites or ions from one side of the membrane to the other was greatly suppressed in the host harboring FgV1-DK21. This indicates that virus infection affects the transport of many micro- and macroelements in host cells at the transcript level. Moreover, this transport system mediates cell-to-cell communication within the host via plasma membranes. For example, transcripts required for cellular communication were highly accumulated at $36 \mathrm{~h}$, suggesting that the virus might first stimulate cell-to-cell communication in fungal host cells, which is necessary to trigger host defense mechanisms against viral pathogens. Indeed, a recent study reported that infection of chlorovirus, Paramecium bursaria chlorella virus 1 , affects the transport activity of solutes via plasma membranes in Chlorella [43]. Plasma membranes are the first barriers to block pathogen attack and can transmit information and molecules between neighboring cells. Viruses utilize plasma membranes to interact with signaling molecules. A previous study suggested that virus infection causes depolarization of the host cell membranes, thus decreasing the transport of solutes by active transporters via plasma membranes [43]. The impairment of plasma membranes by viruses suggests that all materials required for virus replication should be recruited within the host cell [43]. Taken together, these data suggest that FgV1-DK21 might inhibit the transport of diverse metabolites via plasma membranes to the maximize energy required for virus replication within the nucleolus.

Fungal-specific TFs are key players in the gene expression regulation in F. graminearum harboring FgV1-DK21

The expressions of members of the Zn2Cys6 TF family were strongly altered at both the early and late time points. These are known to be fungal-specific, and their functional roles are diverse, including sugar and amino acid metabolism, gluconeogenesis, respiration, vitamin synthesis, cell cycle, chromatin remodeling, nitrogen utilization, peroxisome proliferation, drug resistance, and stress response [30]. The Zn2Cys6 family is the largest TF family in $F$. graminearum, comprising 309 TFs. Of the nine TFs that were differentially expressed at both the early and late time points, six belong to the Zn2Cys6 family, indicating that expression of Zn2Cys6 is necessary in the host harboring FgV1-DK21. Furthermore, the enriched GO terms for nucleic acid binding that were up-regulated at $36 \mathrm{~h}$ provide evidence for transcriptional regulation by TFs such as the Zn2Cys6 TF family (Figure 9). To characterize the functional roles of the 


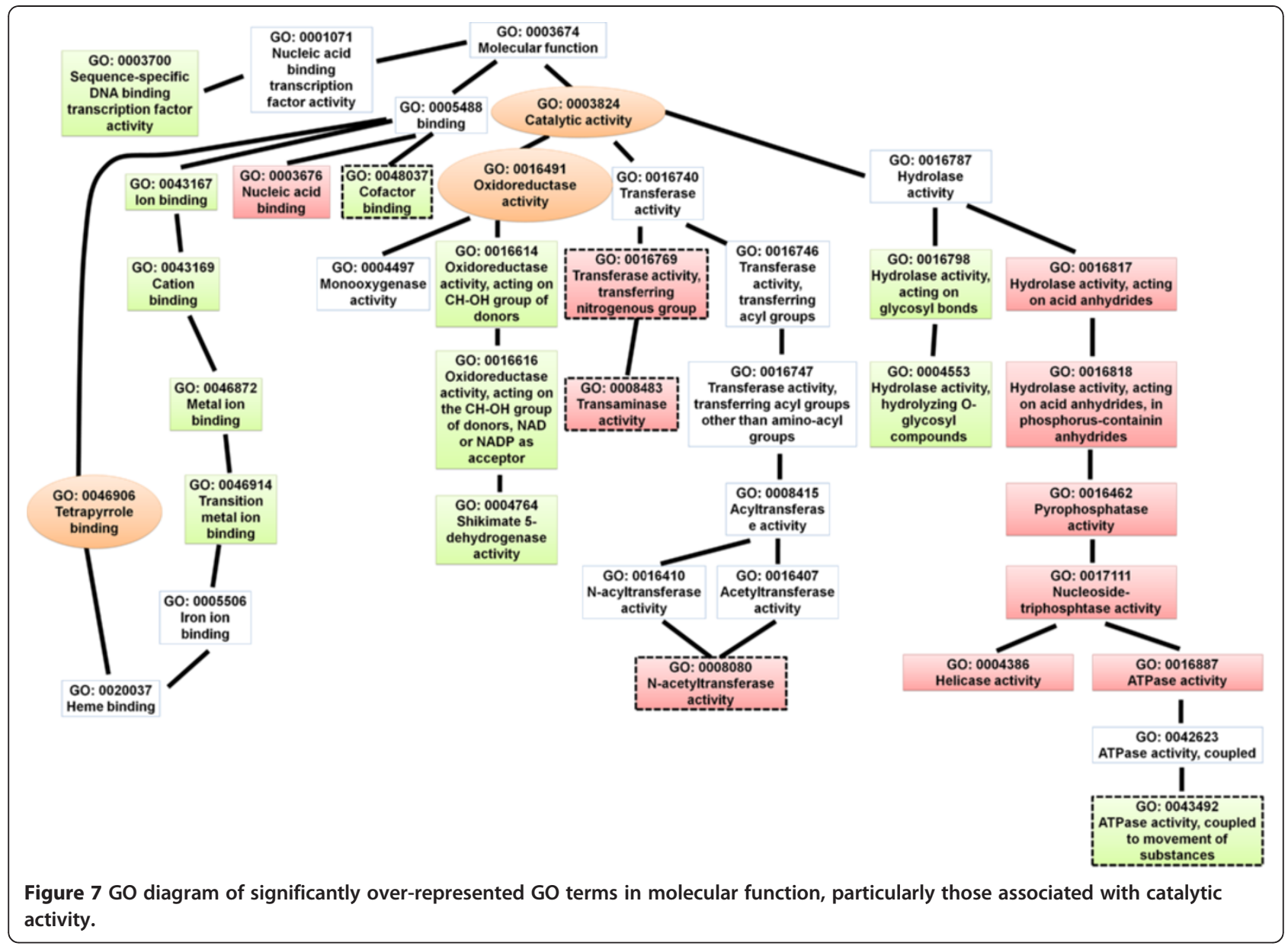

Zn2Cys6 TF family associated with FgV1-DK21, it is necessary to examine the phenotypes of knock-out mutants. Therefore, the recently generated $F$. graminearum deletion mutant lines will be very useful resources for characterizing the functions of host TFs associated with hypovirulence.

\section{FgV1-DK21 triggers CAMP-mediated signal transduction in host cells}

Fungi utilize cAMP-mediated signal transduction pathways to recognize and respond to diverse environmental stimuli. cAMP signaling is implicated in the regulation of hyphal growth, mating, and gluconeogenesis in many fungi $[44,45]$. In addition, cAMP and the G-protein alpha subunit coordinate their activities to regulate differentiation and virulence in some fungi. We found that transcripts for genes associated with responses to cAMP were highly accumulated in the late stage of virus infection. This result is consistent with previous data that suggested up-regulation of cAMP levels in the fungal transcriptome by hypovirus infection [46]. Thus, we hypothesize that FgV1-DK21 attenuates the pathogenicity of $F$. graminearum via cAMP-mediated signaling and that this process occurs relatively late after virus infection.

\section{Conclusions}

Recent years have seen extraordinary developments in genome-wide experimental methods. Of these, microarray analyses facilitate an understanding of the dynamic gene expression patterns of target organisms during environmental stimuli such as biotic and abiotic stresses. Here, given the benefits of the available whole genome sequences of $F$. graminearum, we generated a 3' tiling microarray system covering whole genes. To decipher global transcriptional reprogramming in $F$. graminearum harboring FgV1-DK21 in detail, samples were harvested at two different time points, thus providing lists of differentially expressed genes early and late in the host containing FgV1-DK21 as compared to an uninfected strain. Numbers of differentially expressed genes at the early and late time points were comparable, but the gene lists differed, suggesting time-dependent transcriptional changes. Genes that were up-regulated at the early time point included those involved in protein synthesis, such as ribosome assembly, as well as nucleolus and ribosomal RNA-processing genes, suggesting that FgV1-DK21 strongly modulates translational machinery in $F$. graminearum to maximize viral replication. Moreover, the accumulation of transcripts 


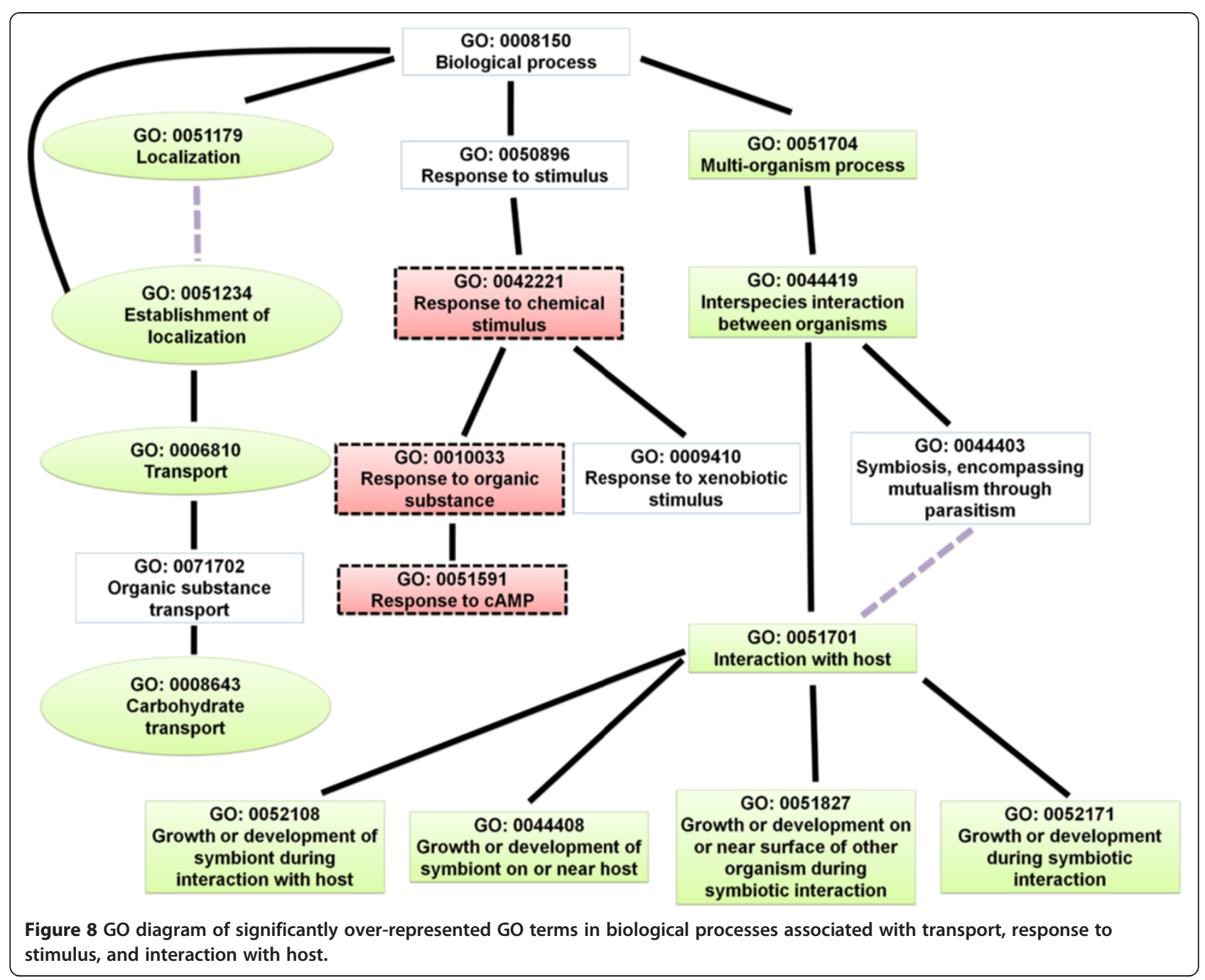

associated with transcription, such as TFs, indicated that the transcriptional machinery, which is largely regulated by fungal-specific TFs, might be one of the main targets for virus infection. In contrast, genes involved in various metabolic pathways, particularly those that produce carboxylic acids, aromatic amino acids, nitrogen compounds, and polyamines, were highly down-regulated at the early time point $(36 \mathrm{~h})$. Interestingly, such components are closely associated with the host defense mechanism. These results suggest that FgV1-DK21 suppresses the production of such defense-related components until the transcriptional and translational machinery in host cells have adjusted to FgV1-DK21 replication. In addition, transport systems associated with membranes were severely damaged by hindering the recruitment of materials for viral replication within host cells. When faced with viral infection, F. graminearum tries to establish a defense mechanism by consistently up-regulating genes associated with defense and virulence at the late time point $(120 \mathrm{~h})$. Taken together, our data provide strong genome-wide transcriptional evidence of how FgV1-DK21 regulates the transcriptional reprogramming in F. graminearum.

\section{Methods}

Fungal strains and growth conditions

Virus-free and FgV1-DK21-infected F. graminearum strain-DK21 were stored in $15 \%(\mathrm{v} / \mathrm{v})$ glycerol at $-80^{\circ} \mathrm{C}$ and reactivated on PDA at $25^{\circ} \mathrm{C}$ with a $12 \mathrm{~h}$ light-dark cycle. F. graminearum cultures used for RNA extractions were grown as described previously [9]. Freshly grown mycelia from PDA media plates were inoculated in 50 or $200 \mathrm{ml}$ complete media (CM) broth [6] and incubated at $25^{\circ} \mathrm{C}$ for $36 \mathrm{~h}$ or $120 \mathrm{~h}$ in an orbital shaker (150 rpm). Hyphae were collected by filtering through 3MM paper, washed with distilled water, dried by blotting with paper towels, and frozen at $-80^{\circ} \mathrm{C}$.

\section{Trichothecene analysis}

Conidia of virus-free and FgV1-DK21-infected F. graminearum strains were harvested in $50 \mathrm{ml}$ of CMC broth 


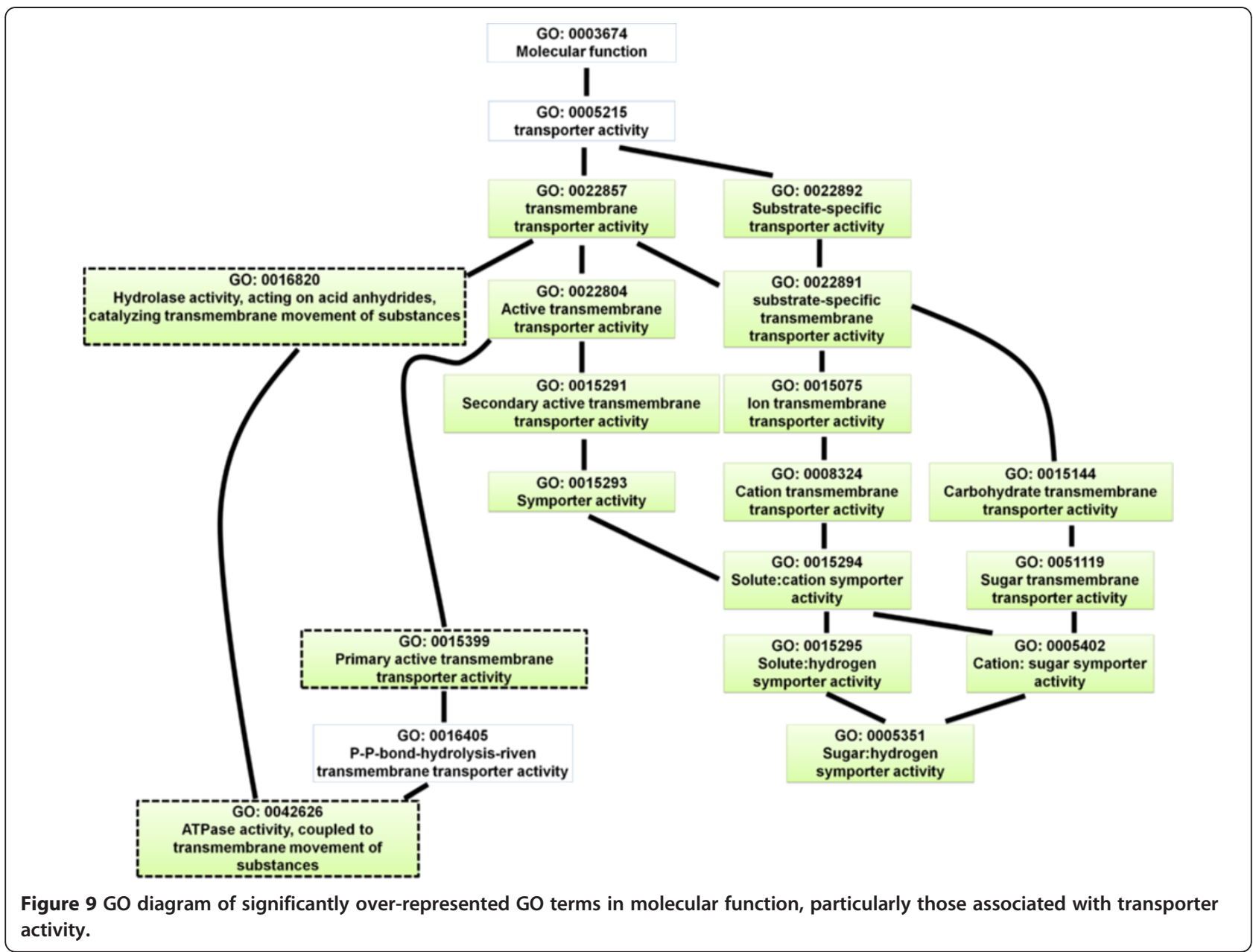

at 4 days after inoculation. Conidial suspensions $(2 \times 105$ conidia per dish) were grown in $20 \mathrm{ml}$ of defined media containing $5 \mathrm{mM}$ of agmatine [47] in $90 \times 15 \mathrm{~mm}$ Petri dishes for 7 days prior to filtrate harvests. Three replicates were used for this treatment. Mycotoxin was extracted from the isolates and analyzed with a Shimadzu QP-5000 gas chromatograph-mass spectrometer, as described previously [48]. The trichothecenes were measured based on biomass produced by each strain.

\section{Preparation of total RNA samples and CDNA synthesis for RT-PCR}

Frozen mycelia were pulverized with a mortar and pestle using liquid nitrogen for nucleic acid extraction. Total RNAs were extracted by Iso-RNA Lysis reagent (5 PRIME, Germany). Extracted total RNA was treated with DNase I (Takara, Japan) to remove genomic DNA according to the instructions provided by the manufacturer. These total RNA samples were precipitated with ethanol and resuspended in DEPC-treated water. Next, $5 \mu \mathrm{g}$ total RNA of each sample was used to synthesize first-strand cDNA with an oligo (dT) $)_{18}$ primer and M-MLV reverse transcriptase (Promega, USA) according to the manufacturer's protocols. All synthesized cDNAs were diluted 1:10 with nucleasefree water for RT-PCR.

\section{Probe design}

Expression profiling was conducted with the Gibberella zeae 135k Microarray, which was designed based on the F. graminearum sequences released in March 2007 (http://www.broad.mit.edu/annotation/genome/fusarium group/). The genome contains a total of 13,382 genes. Ten 60-nucleotide-long probes were designed from each gene starting 250 base pairs (bp) ahead of the end of the stop codon and by shifting $10 \mathrm{bp}$. Thus, these 10 probes covered $150 \mathrm{bp}$ in the $3^{\prime}$ region of the target gene. Mitochondrial genes (50 genes) and selected markers such as $g f p$, gus, hyg, bar, and kan were included. In total, 133,612 probes were designed. The average probe size was 60 nucleotides long, and the $\mathrm{Tm}$ values were adjusted from 75 to $85^{\circ} \mathrm{C}$. The microarray was manufactured by NimbleGen Inc. (http://www.nimblegen.com/). 
Random GC probes $(40,000)$ to monitor the hybridization efficiency and four corner fiducial controls (225) to assist with overlaying the grid on the image were included.

\section{cDNA synthesis and microarray hybridization}

To assess the reproducibility of the microarray analysis, we repeated the experiment three times with independently prepared total RNAs. Thus, a total of 12 samples were subjected to total RNA isolation and used for microarray analyses. For the synthesis of double-stranded cDNAs, the RevertAidTM H Minus First Strand cDNA Synthesis Kit (Fermentas, Lithuania) was used. In brief, $1 \mu$ l oligo dT primer $(100 \mu \mathrm{M})$ and $10 \mu \mathrm{l}(10 \mu \mathrm{g})$ total RNAs were combined and denatured at $70^{\circ} \mathrm{C}$ for $5 \mathrm{~min}$ and renatured by cooling the mixture in ice. First-strand DNA was synthesized by adding $4 \mu \mathrm{l} 5 \mathrm{X}$ First Strand Buffer, $1 \mu \mathrm{l}$ RiboLockTM Ribonuclease Inhibitor, $2 \mu \mathrm{l} 10 \mathrm{mM}$ dNTP mix, and $1 \mu \mathrm{l}$ RevertAidTM H Minus M-MuLV Reverse Transcriptase enzyme and incubating at $42^{\circ} \mathrm{C}$ for $1 \mathrm{~h}$. The reaction was stopped by heating at $70^{\circ} \mathrm{C}$ for $10 \mathrm{~min}$. To synthesize the second strand, $66.7 \mu \mathrm{l}$ nuclease free water, $5 \mu \mathrm{l} 10 \mathrm{X}$ reaction buffer for DNA Polymerase I (Fermentas, Lithuania), $5 \mu \mathrm{l} 10 \mathrm{X}$ T4 DNA ligase buffer (Takara, Japan), $3 \mu \mathrm{l} 10$ unit/ul DNA Polymerase I (Fermentas, Lithuania), $0.2 \mu \mathrm{l} 5$ unit/ $\mu$ l Ribonuclease $\mathrm{H}$ (Fermentas, Lithuania), and $0.1 \mu \mathrm{l} 350 \mathrm{unit} / \mu \mathrm{l}$ T4 DNA ligase (Takara, Japan) were added to the firststrand reaction mixture and the reaction was performed at $15^{\circ} \mathrm{C}$ for $2 \mathrm{~h}$. The double-stranded cDNA mixture was purified using the MinElute Reaction Cleanup Kit (QIAGEN, USA). For the synthesis of Cy3-labeled target DNA fragments, $1 \mu \mathrm{g}$ double-stranded cDNA was mixed with $30 \mu \mathrm{l}$ (1 optical density) Cy3-9mer primer (Sigma-Aldrich, USA) and denatured by heating at $98^{\circ} \mathrm{C}$ for $10 \mathrm{~min}$. The reaction was further proceeded by adding $10 \mu \mathrm{l} 50 \mathrm{X}$ dNTP mix (10 mM each), $8 \mu$ l deionized water, and $2 \mu \mathrm{l}$ Klenow fragment (50 unit/ $\mu$ l, Takara, Japan) and incubating at $37^{\circ} \mathrm{C}$ for $2 \mathrm{~h}$. DNA was precipitated by centrifugation at $12,000 \times g$ after adding $11.5 \mu \mathrm{l} 5 \mathrm{M} \mathrm{NaCl}$ and $110 \mu \mathrm{l}$ isopropanol. Precipitated samples were rehydrated with $13 \mu \mathrm{l}$ water. The concentration of each sample was determined using a spectrophotometer. A $10 \mu \mathrm{g}$ aliqout of DNA was used for microarray hybridization. The sample was mixed with $19.5 \mu \mathrm{l} 2 \mathrm{X}$ hybridization buffer (Nimblegen, USA) and finalized to $39 \mu$ with deionized water. Hybridization was performed with an MAUI chamber (Biomicro, USA) at $42^{\circ} \mathrm{C}$ for $16-18 \mathrm{~h}$. After hybridization, the microarray was removed from the MAUI Hybridization Station and immediately immersed in a shallow $250 \mathrm{ml}$ Wash I (Nimblegen, USA) at $42^{\circ} \mathrm{C}$ for 10-15 s with gentle agitation, then transferred to a second dish of Wash I and incubated for 2 min with gentle agitation. The microarray chip was then transferred to another dish of Wash II and further washed in Wash III for 1 min with agitation. The slide was dried in a centrifuge for $1 \mathrm{~min}$ at $500 \mathrm{~g}$ and scanned using a GenePix scanner 4000B (Axon, USA).

\section{Data analysis}

The hybridized microarray chip was scanned with Genepix 4000 B (Axon Instruments) preset with a $5 \mu \mathrm{m}$ resolution for the Cy3 signal. Signals were digitized and analyzed by Nimblescan (Nimblegen, USA). The grid was aligned to the image with a chip design file called the NDF file. The alignment was assessed by ensuring that the grid's corners were overlaid on the image corners. This was further checked by uniformity scores in the program. The analysis was performed in a two-part process. First, pair-report files were generated in which the sequence, probe, and signal intensity information for the Cy3 channel were collected. Databased background subtraction using a local background estimator was performed to improve fold-change estimates on arrays with high background signals. The data were normalized and processed with a cubic spline normalization using quantiles to adjust for signal variation between chips [49]. A probe-level summarization by Robust Multi-Chip Analysis (RMA) using a median polish algorithm implemented in NimbleScan was used to produce call files in order to improve the sensitivity and reproducibility of microarray results [50].

The multiple correction analysis was performed using the limma package in an R computing environment [51]. Linear models implemented in lmFit and empirical Bayes methods implemented in eBayes were applied to assess the differential expression of genes. Genes for which the adjusted P-value or false discovery rate was below 0.05 were collected and further selected. Hierarchical clustering was performed by Acuity 3.1 (Axon Instruments) with similarity metrics based on squared Euclidean correlation, and average linkage clustering was used to calculate the distance of genes. The microarray data were deposited in the NCBI Gene Expression Omnibus (GEO) database with the Accession Number GSE30545.

\section{GO enrichment analysis}

To gain insight into the functions of the differentially expressed genes, GO enrichment analysis was conducted with GOMINER [52,53]. The 8,338 genes were matched to the $M$. grisea sequencing assembly SC5 (http://www. broad.mit.edu/annotation/genome/magnaporthe_grisea/) with scores of 100 and up by BlastP analysis and were used as the total gene set for GO enrichment analysis. The GOMINER program first categorizes each gene according to its GO terms and the mode of gene expression (either down- or up-regulation). Modes of expressions are denoted as under, over, and change. The program then calculates P-values using a one-sided Fisher exact test for the number of categorized GO terms out of the total number of terms. False discovery 
rate (FDR) values were obtained from 100 randomizations. GO terms for which the FDR was less than 0.05 were selected.

\section{qRT-PCR analysis}

qRT-PCR was performed on Bio-Rad's CFX96 ${ }^{\mathrm{TM}}$ Real-time PCR system using gene-specific internal primers. Each reaction mix $(10 \mu \mathrm{l})$ consisted of $25 \mathrm{ng}$ total cDNA, $5 \mu \mathrm{l} 2 \mathrm{X}$ SsoFast ${ }^{\mathrm{TM}}$ EvaGreen ${ }^{\circledR}$ Supermix (Bio-Rad, USA), and 10 pmoles each primer. The thermal profile was as follows: $3 \mathrm{~min}$ at $95^{\circ} \mathrm{C}$ and 40 cycles of $5 \mathrm{~s}$ at $95^{\circ} \mathrm{C}, 5 \mathrm{~s}$ at $58^{\circ} \mathrm{C}$, and melting curve data obtained by increasing the temperature from 65 to $95^{\circ} \mathrm{C}$. Elongation factor $1 \alpha(\mathrm{EF}-1 \alpha$; FGSG_08811) and cyclophilin (Cyp1; FGSG_07439) were used as internal reference genes to normalize mRNA levels between samples (EF-1 $\alpha$; GenBank accession No. XM388987, Cyp1; GenBank accession No. XM387615). Data were analyzed using the Bio-Rad CFX Manager V1.6.541.1028 software (Bio-Rad, USA). RNA was extracted from three independent replicate experiments, and each PCR product was evaluated in at least three independent experiments, including three technical replicates [54].

\section{Additional files}

Additional file 1: Table S1. Differentially expressed F. graminearum

genes at $36 \mathrm{~h}$

Additional file 2: Table S2. Differentially expressed F. graminearum genes at $120 \mathrm{~h}$.

Additional file 3: Table S3. The 20 representative $F$. graminearum genes selected for qRT-PCR validation.

Additional file 4: Table S4. Oligonucleotide primers used for qRT-PCR.

Additional file 5: Table S5. Enriched GO terms of differentially expressed genes.

Additional file 6: Table S6. F. graminearum transcription factors which were differentially expressed by FgV1-DK21 infection.

\section{Abbreviations}

h: Hours post inoculation; FgV1-DK21: Fusarium graminearum virus 1 strain DK21; TF: Transcription factor; GO: Gene ontology.

\section{Competing interests}

The authors declare that they have no competing interests.

\begin{abstract}
Authors' contributions
$J Y, K M L, M S, Y W L$, and KK designed the experiment. JY, KML, and MS performed cultivation of F. graminearum and infection with FgV1-DK21. JY and KM conducted mycotoxin analysis, isolated total RNAs, and conducted RT-PCR. WKC, JY, and KK analyzed the microarray data and interpreted the results. JY and $\mathrm{KK}$ coordinated the study. WKC, JY, YWL, and KK wrote the manuscript. All authors read and approved the final manuscript.
\end{abstract}

\section{Acknowledgments}

This research was supported by grants from the Center for Fungal Pathogenesis (No. 20110000959) funded by the Ministry of Education, Science, and Technology (MEST) and the Next-Generation BioGreen 21 Program (Nos. PJ00819801 \& PJ00798402), Rural Development Administration, Republic of Korea. WKC, JY, KML, and MS were supported by research fellowships from the MEST through Brain Korea 21 Project.
Received: 3 October 2011 Accepted: 15 February 2012

Published: 6 May 2012

\section{References}

1. Walter S, Nicholson P, Doohan FM: Action and reaction of host and pathogen during Fusarium head blight disease. New Phytol 2010, 185(1):54-66.

2. Fung F, Clark RF: Health effects of mycotoxins: a toxicological overview. $J$ Toxicol Clin Toxicol 2004, 42(2):217-234.

3. Lee T, Oh D-W, Kim H-S, Lee J, Kim Y-H, Yun S-H, Lee Y-W: Identification of deoxynivalenol- and nivalenol-producing chemotypes of Gibberella zea by using PCR. Appl Environ Microbiol 2001, 67(7):2966-2972

4. Urban M, Daniels S, Mott E, Hammond-Kosack K: Arabidopsi is susceptible to the cereal ear blight fungal pathogens Fusarium graminearu and Fusarium culmoru. Plant J 2002, 32(6):961-973.

5. Mayo MA: A summary of taxonomic changes recently approved by ICTV. Arch Virol 2002, 147(8):1655-1663.

6. Chu Y-M, Jeon J-J, Yea S-J, Kim Y-H, Yun S-H, Lee Y-W, Kim K-H: Double-stranded RNA mycovirus from Fusarium graminearu. Appl Environ Microbiol 2002 68(5):2529-2534

7. Compel P, Papp I, Bibo M, Fekete C, Hornok L: Genetic interrelationships and genome organization of double-stranded RNA elements of Fusarium poa. Virus Genes 1999, 18(1):49-56.

8. Nogawa M, Kageyama T, Nakatani A, Taguchi G, Shimosaka M, Okazaki M: Cloning and characterization of mycovirus double-stranded RNA from the plant pathogenic fungus, Fusarium solani f. sp. robiniae. Biosci Biotechnol Biochem 1996, 60(5):784-788.

9. Kwon S-J, Lim W-S, Park S-H, Park M-R, Kim K-H: Molecular characterization of a dsRNA mycovirus, Fusarium graminearum virus-DK21, which is phylogenetically related to hypoviruses but has a genome organization and gene expression strategy resembling those of plant potex-like viruses. Mol Cells 2007, 23(3):304-315.

10. Yu J, Kwon S-J, Lee K-M, Son M, Kim K-H: Complete nucleotide sequence of double-stranded RNA viruses from Fusarium graminearu strain DK3. Arch Virol 2009, 154(11):1855-1858.

11. Darissa O, Willingmann P, Schafer W, Adam G: A novel double-stranded RNA mycovirus from Fusarium graminearu: nucleic acid sequence and genomic structure. Arch Virol 2011, 156(4):647-658.

12. $\mathrm{Yu}$ J, Lee K-M, Son M, Kim K-H: Molecular characterization of Fusarium graminearum virus 2 Isolated from Fusarium graminearu strain 98-8-60. Plant Pathology J 2011, 27(3):285-290.

13. Milgroom MG, Cortesi P: Biological control of chestnut blight with hypovirulence: a critical analysis. Annu Rev Phytopathol 2004, 42:311-338.

14. Ghabrial SA, Suzuki N: Viruses of plant pathogenic fungi. Annu Rev Phytopathol 2009, 47:353-384.

15. Lee K-M, Yu J, Son M, Lee Y-W, Kim K-H: Transmission of Fusarium boothi Mycovirus via Protoplast Fusion Causes Hypovirulence in Other Phytopathogenic Fungi. PLoS One 2011, 6(6):e21629.

16. $X u$ JR, Peng $Y L$, Dickman MB, Sharon A: The dawn of fungal pathogen genomics. Annu Rev Phytopathol 2006, 44:337-366.

17. Paper JM, Scott-Craig JS, Adhikari ND, Cuomo CA, Walton JD: Comparative proteomics of extracellular proteins in vitro and in planta from the pathogenic fungus Fusarium graminearu. Proteomics 2007, 7(17):3171-3183.

18. Choi YE, Shim WB: Identification of genes associated with fumonisin biosynthesis in Fusarium verticillioide via proteomics and quantitative real-time PCR. J Microbiol Biotechnol 2008, 18(4):648-657.

19. Moretti M, Grunau A, Minerdi D, Gehrig P, Roschitzki B, Eberl L, Garibaldi A Gullino ML, Riedel K: A proteomics approach to study synergistic and antagonistic interactions of the fungal-bacterial consortium Fusarium oxysporu wild-type MSA 35. Proteomics 2010, 10(18):3292-3320.

20. Kwon S-J, Cho S-Y, Lee K-M, Yu J, Son M, Kim K-H: Proteomic analysis of fungal host factors differentially expressed by Fusarium graminearu infected with Fusarium graminearum virus-DK21. Virus Res 2009 144(1-2):96-106.

21. Guldener U, Seong KY, Boddu J, Cho S, Trail F, Xu JR, Adam G, Mewes HW Muehlbauer GJ, Kistler HC: Development of a Fusarium graminearu Affymetrix GeneChip for profiling fungal gene expression in vitro and in planta. Fungal Genet Biol 2006, 43(5):316-325. 
22. Becher R, Weihmann F, Deising HB, Wirsel SG: Development of a novel multiplex DNA microarray for Fusarium graminearu and analysis of azole fungicide responses. BMC Genomics 2011, 12:52.

23. Kristensen R, Gauthier G, Berdal KG, Hamels S, Remacle J, Holst-Jensen A: DNA microarray to detect and identify trichothecene- and moniliforminproducing Fusariu species. J Appl Microbio/ 2007, 102(4):1060-1070.

24. Qi W, Kwon C, Trail F: Microarray analysis of transcript accumulation during perithecium development in the filamentous fungus Gibberella zea (anamorph Fusarium graminearu). Mol Genet Genomics 2006, 276(1):87-100.

25. Nicolaisen M, Justesen AF, Thrane U, Skouboe P, Holmstrom K: An oligonucleotide microarray for the identification and differentiation of trichothecene producing and non-producing Fusariu species occurring on cereal grain. J Microbiol Methods 2005, 62(1):57-69.

26. Ma LJ, van der Does HC, Borkovich KA, Coleman JJ, Daboussi MJ, Di Pietro A, Dufresne M, Freitag M, Grabherr M, Henrissat B, et al: Comparative genomics reveals mobile pathogenicity chromosomes in Fusariu. Nature 2010, 464(7287):367-373.

27. Allen TD, Nuss DL: Specific and common alterations in host gene transcript accumulation following infection of the chestnut blight fungus by mild and severe hypoviruses. J Virol 2004, 78(8):4145-4155.

28. Dawe AL, Segers GC, Allen TD, McMains VC, Nuss DL: Microarray analysis of Cryphonectria parasitic Ga- and Gßy-signalling pathways reveals extensive modulation by hypovirus infection. Microbiology 2004, 150(Pt 12):4033-4043.

29. Deng F, Allen TD, Hillman BI, Nuss DL: Comparative analysis of alterations in host phenotype and transcript accumulation following hypovirus and mycoreovirus infections of the chestnut blight fungus Cryphonectria parasitic. Eukaryot Cell 2007, 6(8):1286-1298.

30. Shelest E: Transcription factors in fungi. FEMS Microbiol Lett 2008, 286(2):145-151.

31. Park J, Jang S, Kim S, Kong S, Choi J, Ahn K, Kim J, Lee S, Park B, Jung K, et al: FTFD: an informatics pipeline supporting phylogenomic analysis of fungal transcription factors. Bioinformatics 2008, 24(7):1024-1025.

32. Son H, Seo YS, Min K, Park AR, Lee J, Jin JM, Lin Y, Cao P, Hong SY, Kim EK, et al: A phenome-based functional analysis of transcription factors in the cereal head blight fungus, Fusarium graminearu. PLoS Pathog 2011, 7(10):e1002310.

33. Nemeth A, Langst G: Genome organization in and around the nucleolus Trends Genet 2011, 27(4):149-156.

34. Kim SH, Ryabov EV, Brown JW, Taliansky M: Involvement of the nucleolus in plant virus systemic infection. Biochem Soc Trans 2004, 32(4):557-560.

35. Lopez-Lastra M, Ramdohr P, Letelier A, Vallejos M, Vera-Otarola J, ValienteEcheverria F: Translation initiation of viral mRNAs. Rev Med Virol 2010, 20(3):177-195.

36. Emmott E, Smith C, Emmett SR, Dove BK, Hiscox JA: Elucidation of the avian nucleolar proteome by quantitative proteomics using SILAC and changes in cells infected with the coronavirus infectious bronchitis virus. Proteomics 2010, 10(19):3558-3562.

37. Emmott E, Wise H, Loucaides EM, Matthews DA, Digard P, Hiscox JA: Quantitative proteomics using SILAC coupled to LC-MS/MS reveals changes in the nucleolar proteome in influenza A virus-infected cells. J Proteome Res 2010, 9(10):5335-5345.

38. Hiscox JA: RNA viruses: hijacking the dynamic nucleolus. Nat Rev Microbiol 2007, 5(2):119-127.

39. Dawe AL, Van Voorhies WA, Lau TA, Ulanov AV, Li Z: Major impacts on the primary metabolism of the plant pathogen Cryphonectria parasitic by the virulence-attenuating virus CHV1-EP713. Microbiology 2009, 155(12):3913-3921.

40. Madhani HD, Fink GR: The control of filamentous differentiation and virulence in fungi. Trends Cell Biol 1998, 8(9):348-353.

41. Gill SS, Tuteja N: Polyamines and abiotic stress tolerance in plants. Plant Signal Behav 2010, 5(1):26-33.

42. Garriz A, Gonzalez ME, Marina M, Ruiz OA, Pieckenstain FL: Polyamine metabolism during sclerotial development of Sclerotinia sclerotioru. Mycol Res 2008, 112(3):414-422.

43. Agarkova I, Dunigan D, Gurnon J, Greiner T, Barres J, Thiel G, Van Etten JL: Chlorovirus-mediated membrane depolarization of Chlorella alters secondary active transport of solutes. J Virol 2008, 82(24):12181-12190.
44. D'Souza CA, Heitman J: Conserved cAMP signaling cascades regulate fungal development and virulence. FEMS Microbiol Rev 2001, 25(3):349-364

45. Wang $P$, Heitman J: Signal transduction cascades regulating mating, filamentation, and virulence in Cryptococcus neoforman. Curr Opin Microbiol 1999, 2(4):358-362.

46. Chen B, Gao S, Choi GH, Nuss DL: Extensive alteration of fungal gene transcript accumulation and elevation of G-protein-regulated cAMP levels by a virulence-attenuating hypovirus. Proc Natl Acad Sci USA 1996 93(15):7996-8000.

47. Gardiner DM, Kazan K, Manners JM: Nutrient profiling reveals potent inducers of truncothecene biosynthesis in Fusarium graminearu. Fungal Genet Biol 2009, 46(8):604-613.

48. Son $H$, Lee J, Park AR, Lee Y-W: ATP citrate lyase is required for normal sexual and asexual development in Gibberella zea. Fungal Genet Biol 2011, 48(4):408-417.

49. Workman $C$, Jensen $L$, Jarmer $H$, Berka R, Gautier L, Nielser HB, Saxild HH, Nielsen C, Brunak S, Knudsen S: A new non-linear normalization method for reducing variability in DNA microarray experiments. Genome Biol 2002, 3(9):48.

50. Irizarry RA, Hobbs B, Collin F, Beazer-Barclay YD, Antonellis KJ, Scherf U, Speed TP: Exploration, normalization, and summaries of high density oligonucleotide array probe level data. Biostatistics 2003, 4(2):249-264.

51. Smyth GK: Linear models and empirical bayes methods for assessing differential expression in microarray experiments. Stat Appl Genet Mol Biol 2004, 3:Article3.

52. Zeeberg BR, Feng W, Wang G, Wang MD, Fojo AT, Sunshine M, Narasimhan S, Kane DW, Reinhold WC, Lababidi S, et al: GoMiner: a resource for biological interpretation of genomic and proteomic data. Genome Biol 2003, 4(4):R28.

53. Ashburner M, Ball CA, Blake JA, Botstein D, Butler H, Cherry JM, Davis AP Dolinski K, Dwight SS, Eppig JT, et al: Gene ontology: tool for the unification of biology. The Gene Ontology Consortium. Nat Genet 2000, 25(1):25-29

54. Ruepp A, Zollner A, Maier D, Albermann K, Hani J, Mokrejs M, Tetko I, Guldener U, Mannhaupt G, Munsterkotter M, et al: The FunCat, a functional annotation scheme for systematic classification of proteins from whole genomes. Nucleic Acids Res 2004, 32(18):5539-5545.

doi:10.1186/1471-2164-13-173

Cite this article as: Cho et al:: Genome-wide expression profiling shows transcriptional reprogramming in Fusarium graminearum by Fusarium graminearum virus 1-DK21 infection. BMC Genomics 2012 13:173.

\section{Submit your next manuscript to BioMed Central and take full advantage of:}

- Convenient online submission

- Thorough peer review

- No space constraints or color figure charges

- Immediate publication on acceptance

- Inclusion in PubMed, CAS, Scopus and Google Scholar

- Research which is freely available for redistribution 